\title{
Health literacy Knowledge and understanding of registered nurses in tertiary care teaching hospital of eastern Nepal: two important dimensions for better health results
}

\author{
Shristi Subedi \\ B.P. Koirala Institute of health sciences \\ subedi.shristi882@gmail.com \\ Anup Ghimire \\ MD in community medicine \\ anup.ghimire@bpkihs.edu \\ Samyog Uprety \\ $\mathrm{MD}$ in community medicine \\ samyog.uprety@bpkihs.edu \\ Paras Kumar Pokhrel \\ B.P. Koirala Institute of health sciences \\ paras.k.pokharel@gmail.com
}

Conflito de interesses: nada a declarar. Financiamento: nada a declarar. 


\section{ABSTRACT}

Background: Difference in health literacy skills among peoples is a cause of health inequality and has a profound effect on health care system. Correlation between health literacy and health outcome of patient subsequently demands identification of patient's health literacy level by health professionals.

Objective: The study aims to assess the health literacy knowledge and understanding of registered nurses working in tertiary care teaching hospital.

Methods: A cross-sectional method was employed among 125 registered nurses. Health Literacy Knowledge and Experience Survey (HLKES-2) was used to gather knowledge related data. Descriptive statistical tools, $t$ Mann-Whitney $U$ test and Kruskal-Wallis $H$ were used to analyze the data. A focus group discussion $(\mathrm{N}=10)$ was conducted to obtain nurses' understanding of health literacy.

Results: Majority of nurses had not heard the term health literacy before. Finding suggest gap in health literacy knowledge among nurses. Knowledge scarcity was in almost all areas but noticeably in evaluation of healthcare teaching. Half of the respondent scored less than $50 \%$ of the total score. Analysis demonstrated that Health literacy knowledge was independent of nurses' characteristics.

Conclusion: limited knowledge of health literacy among nurses stresses for integration of health literacy education in nursing curriculum and continuing education.

Keywords: health literacy, knowledge, understanding 


\section{INTRODUCTION}

Delivering quality health care service to all people is an ultimate objective of any health care systems in the world, irrespective of their individual characteristics (WHO, 2017). Whereas, limited literacy of an individual impacts their health behaviors, decision making capacity for improving health and wellbeing and ultimately, health outcomes (Parker, 2000). Health literacy has become an emerging priority, as Health literacy is linked to better health outcomes as a result of acquisition of new knowledge, more positive attitudes, greater self-efficacy (Baker, 2006). On the other hand, low health literacy can lead to increased disease burden not only for the individual but also for the healthcare system itself (Rudd, 2010).

The Institute of Medicine report defines health literacy as "the extent to which an individuals have the capacity to obtain, process and understand basic health information and services that are necessary to make appropriate health decisions" (Institute of Medicine (US) Committee on Health Literacy, 2004). Similarly, the concept of health literacy constitute various dimensions together with knowledge and competency of understanding, which are important determinants of health literacy (Sørensen et al., 2012).

Health literacy is a concern to everyone involved in disease prevention, health promotion and protection, treatment and policy makers. The reports of limited health literacy prevalent among general population, highlights the importance of health professionals to understand health literacy to identify the low health literacy among patients and use appropriate techniques for better communication as improved communication can lead to better health literacy of patient (Vaz de Almeida \& Belim, 2020). However, health professionals are found having limited understanding of health literacy and of the consequences of low health literacy for their indigenous patients (Lambert et al., 2014).

Studies on health literacy among general and health professions from south Asian countries are sparse. Yet, the limited available data suggest low health literacy is predominant in south Asian population and is associated with education attainment, age, income, socio-economic background, gender, and health behaviors (Rajah et al., 2019; Shrestha et al., 2018). Nursing plays an essential role in direct patient care and in the delivery of health services. Therefore, it is important for nurses to understand health literacy, capable to recognize patient's health literacy level and be prepared to face the challenges while working on patients with limited health literacy (Sofaer \& Schumann, 2013).

Due to the strong association of low health literacy and health outcome of patients (Cavanaugh et al., 2010) and to our best of knowledge, health literacy knowledge and 
practice among nurses from Nepal has not been previously examined. Obtaining baseline knowledge of nurses is important as it would provide some information regarding their understanding of health literacy, lacking areas and will help the concerned authority to formulate strategies in future. Having better understanding of health literacy will allow nursing professionals to be able to work with patients that have limited health literacy skills Also, acknowledged that health literacy as a pivotal determinant of understanding, accessing and using health information and health services and highlighted the important that the health literacy needs of the people to be addressed (Budhathoki et al., 2017) Thus, our objective in this cross-sectional study was to examine registered nurses' knowledge and understanding of health literacy.

\section{METHODS}

\subsection{Study design and sample}

A cross sectional study was conducted among 125 registered nurses working in B.P. Koirala Institute of Health Sciences (BPKIHS), a tertiary care teaching hospital of Nepal, to find the level of health literacy knowledge and understanding, two dimensions of health literacy (Sørensen et al., 2012) among nurses of BPKIHS. Those nurses who had at least bachelor's degree in nursing and working in the clinical setting of BPKIHS were included in this study. Since hospital lacked exact data regarding number of bachelors passed nurses, we went to each ward/units and surveyed the number of nurses who had attained at least bachelor degree in nursing. Then we enrolled all those nurses who were available at the time of study period. A couple of nurses who were on long leaves were left out from study. Nurses other than the inclusion criteria and who do not want to participate in the study were excluded. Face to face interview was conducted to gather data. Ethical clearance was taken from IRC-BPKIHS. Permission was additionally taken from BPKIHS nursing matron and nursing in-charges. Informed consent was taken from participants. The total duration of this study was 6 months (September 2019 to February 2020).

A focus group discussion (FGD) was conducted using focus group discussion guidelines to get wider view of nurses' understanding on health literacy. One focus group discussion was conducted among ten nurses working in different clinical setting of same hospital which lasted about an hour. Consent from the participants was obtained before recording and taking notes. FGD were transcribed and thematic analysis was done. 


\subsection{Instrument}

Structured questionnaire health literacy knowledge and experience survey (HLKES-2), a revised version of HLKES was used to gather data after a permission was obtained. Health literacy questionnaire section included 14 questions covering the content areas: foundational knowledge of health literacy principles, appropriate health literacy communication techniques, expected behaviors of people with low health literacy and evaluation of written materials (Walker et al., 2019).

Pretesting was done in another similar setting. Cultural equivalency was checked, and content validation was done by expert and suggestions were incorporated.

\subsection{Statistical analysis}

The statistical analysis was performed using Statistical Package for Social Sciences for statistical analysis (SPSS) version 11.5. For health literacy knowledge section, a score of 1 point was given to every correct response and 0 to incorrect. Data was checked for normality using the Kolmogrov-Smirmov test and Shapiro-Wilk test. The characteristics of the sample were described using descriptive statistics. Bivariate analysis was explored using non-parametric tests like Mann-Whitney $\mathrm{U}$ test and Kruskal-Wallis $\mathrm{H}$ test to establish the relationship between dependent and independent variables. The probability of significance was set at $5 \%$ level of significance.

\section{RESULTS}

\subsection{Health literacy knowledge level of registered nurses of BPKIHS}

Since nurses in Nepal are predominantly females, most nurses were female in sex (98.4\%). large number of nurses were of groups between 20 and 30 . This could be due to frequent turnover of nurses at hospital due to better opportunity elsewhere, nurse migration and various other reasons ("Perspectives of Developing Nursing Education in Nepal," 2018) (Table I). 
Table I - Difference in Health literacy knowledge score by characteristics of registered nurses of BPKIHS

\begin{tabular}{|c|c|c|c|c|c|}
\hline \multirow[t]{2}{*}{ Variable } & \multirow[t]{2}{*}{ Category } & \multirow[t]{2}{*}{$\mathbf{N}(\%)$} & \multicolumn{3}{|c|}{ Knowledge } \\
\hline & & & $\begin{array}{l}\text { Mean } \\
\text { rank }\end{array}$ & M (IQR) & $\begin{array}{c}\text { P- } \\
\text { value }\end{array}$ \\
\hline \multirow[t]{2}{*}{ Sex } & Female & $\begin{array}{c}123 \\
(98.4)\end{array}$ & 62.8 & $6(2)$ & \multirow[t]{2}{*}{0.6} \\
\hline & Male & $2(1.6)$ & 74.0 & $6.5(3)$ & \\
\hline \multirow[t]{3}{*}{ Age (in years) } & $21-30$ & $\begin{array}{c}84 \\
(67.2)\end{array}$ & 66.1 & $6(2)$ & \multirow[t]{3}{*}{0.2} \\
\hline & $31-40$ & $\begin{array}{c}26 \\
(20.8)\end{array}$ & 52.8 & $5.5(4)$ & \\
\hline & 41 and older & $\begin{array}{c}15 \\
(12.0)\end{array}$ & 63.0 & $6(2)$ & \\
\hline \multirow[t]{5}{*}{ Caste and ethnicity } & Brahman/chettri & $\begin{array}{c}52 \\
(41.6)\end{array}$ & 60.5 & $6(2)$ & \multirow[t]{5}{*}{0.8} \\
\hline & Janjati hill & $\begin{array}{c}28 \\
(22.4)\end{array}$ & 62.8 & $6(2)$ & \\
\hline & Madhesi & $10(8.0)$ & 59.0 & $6(3)$ & \\
\hline & janjati terai & $\begin{array}{c}29 \\
(23.2)\end{array}$ & 66.7 & $6(2)$ & \\
\hline & Others & $6(4.8)$ & 73.4 & $\begin{array}{c}6.5(1.75 \\
)\end{array}$ & \\
\hline \multirow[t]{2}{*}{ Designation } & Nursing staff & $\begin{array}{c}109 \\
(87.2)\end{array}$ & 69.9 & $6(1)$ & \multirow[t]{2}{*}{0.4} \\
\hline & Nursing in-charge & $\begin{array}{c}16 \\
(12.8)\end{array}$ & 61.9 & $6(2)$ & \\
\hline \multirow[t]{8}{*}{ Area of practice } & Emergency & $\begin{array}{c}26 \\
(20.8)\end{array}$ & 63.6 & $6(2.25)$ & \multirow[t]{8}{*}{0.7} \\
\hline & Medicine department & $\begin{array}{c}25 \\
(20.0)\end{array}$ & 61.7 & $6(2)$ & \\
\hline & ICU & $\begin{array}{c}22 \\
(17.6)\end{array}$ & 60.6 & $6(2.25)$ & \\
\hline & Pediatric department & $\begin{array}{c}15 \\
(12.0)\end{array}$ & 56.1 & $6(4)$ & \\
\hline & $\begin{array}{l}\begin{array}{l}\text { obstetrics and gynecology } \\
\text { department }\end{array} \\
\end{array}$ & $10(8.0)$ & 53.8 & $\begin{array}{c}5.50(5.5 \\
0)\end{array}$ & \\
\hline & surgery wards & $10(8.0)$ & 46.1 & $6(1.50)$ & \\
\hline & Orthopedics department & $10(8.0)$ & 64.7 & $6(2)$ & \\
\hline & operation theatre & $7(5.6)$ & 48.07 & $5(4)$ & \\
\hline \multirow{2}{*}{$\begin{array}{l}\text { Highest level of } \\
\text { nursing education }\end{array}$} & Master in nursing & $4(3.2)$ & 62.8 & $6(2.25)$ & \multirow[t]{2}{*}{0.7} \\
\hline & Bachelor in Nursing & $\begin{array}{c}121 \\
(96.8)\end{array}$ & 68.7 & $6(2)$ & \\
\hline \multirow[t]{3}{*}{$\begin{array}{c}\text { Type of bachelor } \\
\text { degree }\end{array}$} & $\mathrm{BN}$ & $\begin{array}{c}49 \\
(39.2)\end{array}$ & 61.3 & $6(2)$ & \multirow[t]{3}{*}{0.8} \\
\hline & BNS & $8(6.4)$ & 66.6 & $6(2.75)$ & \\
\hline & B.Sc. Nursing & $\begin{array}{c}68 \\
(54.4)\end{array}$ & 63.7 & $6(2)$ & \\
\hline \multirow{3}{*}{$\begin{array}{c}\text { University of } \\
\text { bachelor nursing } \\
\text { pass out }\end{array}$} & BPKIHS & $\begin{array}{c}18 \\
(14.4)\end{array}$ & 64.4 & $6(2.25)$ & \multirow[t]{3}{*}{0.9} \\
\hline & Kathmandu university & 16 12.8) & 64.5 & $6(3.75)$ & \\
\hline & Purwanchal university & $\begin{array}{c}50 \\
(40.0)\end{array}$ & 61.3 & $6(2)$ & \\
\hline
\end{tabular}




\begin{tabular}{|c|c|c|c|c|c|}
\hline & Tribhuwan university & $\begin{array}{c}22 \\
(17.6)\end{array}$ & 60.5 & $6(1.25)$ & \\
\hline & Diverse universities & $\begin{array}{c}19 \\
(15.2)\end{array}$ & 67.3 & $6(2)$ & \\
\hline \multirow[t]{6}{*}{$\begin{array}{l}\text { Nursing experience } \\
\text { (in years) }\end{array}$} & Less than 1 year & $\begin{array}{c}13 \\
(10.4)\end{array}$ & 63.0 & $6(3)$ & \multirow[t]{6}{*}{0.8} \\
\hline & $1-5$ & $\begin{array}{c}62 \\
(49.6) \\
\end{array}$ & 64.7 & $6(2.25)$ & \\
\hline & $6-10$ & $\begin{array}{c}20 \\
(16.0)\end{array}$ & 69.0 & $6.50(2)$ & \\
\hline & $11-15$ & $7(5.6)$ & 53.0 & $6(4)$ & \\
\hline & $16-20$ & $10(8.0)$ & 57.4 & $6(2)$ & \\
\hline & More than 20 & $\begin{array}{c}13 \\
(10.4)\end{array}$ & 54.9 & $6(1.50)$ & \\
\hline
\end{tabular}

$\mathrm{N}=$ number, $\%=$ percentage, $\mathrm{M}=$ Median, IQR=Inter quartile range, $\mathrm{BN}=$ Bachelor in Nursing, $\mathrm{BNS}=$ Bachelor in nursing science, BPKIHS= B.P. koirala institute of health sciences,

Response to HLKES-2 questionnaires revealed that, health literacy knowledge score ranged from 0 to 11 . The median and IQR were six and two, respectively. Twenty five percent of participant had scored up to $5,50 \%$ of participant scored less than 6 and $75 \%$ of participants scored up to 7 .

Most of the participants (77.6\%) knew low health literacy is prevalent among older age group. Although 105 (84.0\%) of nurses responded correctly that a patient with adequate health literacy will be able to read, comprehend, and actively participate in decisions and $62.4 \%$ the participants believed that most patients with low health literacy will ask questions if they do not understand, which is not the actual case (Katz et al., 2007). However, when questioned about the nursing consideration while conducting health teaching, only $8.0 \%$ of respondent knew that most patients read 3 to 5 grade levels lower than the last year of school completed. A large amount of respondent (62.4\%) believed that most patients with low health literacy will ask questions if they do not understand information.

Small number of participants (37.6 \%) knew that low health literacy patients are hospitalized more frequently for management of chronic illness than those with adequate health literacy, $29.0 \%$ of nurses considered that patient with low health literacy regularly participate in preventive healthcare. Bulk of participants $(92.0 \%)$ responded that nurses should prioritize using simple language when conducting health teaching.

Only $35.2 \%$ participants were aware that patients with low health literacy may avoid asking questions. Moreover, only $30.0 \%$ of nurses presume that these patients often seek health care prematurely and $24.0 \%$ participant thought patient with low health literacy will readily admit difficulty reading. Only $6.8 \%$ of participants knew that teach-Back is the most 
effective strategy for nurses to establish a patient's understanding and evaluate the effectiveness of healthcare teaching (Table II).

Table II: Frequency and percentage of responses to health literacy knowledge section by registered nurses $(N=125)$

$\begin{array}{llllll}\mathbf{S} & \text { Health literacy questions } & \text { A } & \text { B } & \text { C } & \text { D } \\ \mathbf{N} & & & & & \end{array}$

\begin{tabular}{|c|c|c|c|c|c|}
\hline & & \multicolumn{4}{|c|}{$\mathrm{N}(\%)$} \\
\hline 1 & $\begin{array}{l}\text { Low health literacy is most prevalent among which age } \\
\text { group? }\end{array}$ & $\begin{array}{c}15 \\
(12.0 \%)\end{array}$ & $\begin{array}{c}4 \\
(3.2 \%)\end{array}$ & $9(7.2 \%)$ & $\begin{array}{c}97 \\
(77.6 \%)\end{array}$ \\
\hline 2 & A patient with adequate health literacy will be able to: & $\begin{array}{c}8 \\
(6.4 \%)\end{array}$ & $\begin{array}{c}9 \\
(7.2 \%)\end{array}$ & $\begin{array}{c}105 \\
(84.0 \%)\end{array}$ & $3(2.4 \%)$ \\
\hline 3 & $\begin{array}{l}\text { What should the nurse consider when conducting } \\
\text { health teaching with a patient? }\end{array}$ & $\begin{array}{c}24 \\
(19.2 \%)\end{array}$ & $\begin{array}{c}10 \\
(8.0 \%)\end{array}$ & $\begin{array}{c}78 \\
(62.4 \%)\end{array}$ & $\begin{array}{c}13 \\
(10.4 \%)\end{array}$ \\
\hline 4 & $\begin{array}{l}\text { What is the likelihood that a nurse will encounter a } \\
\text { patient with low health literacy? }\end{array}$ & $\begin{array}{c}47 \\
(37.6 \% \\
)\end{array}$ & $\begin{array}{c}51 \\
(40.8 \%)\end{array}$ & $\begin{array}{c}13 \\
(10.4 \%)\end{array}$ & $\begin{array}{c}14 \\
(11.2 \%)\end{array}$ \\
\hline 5 & $\begin{array}{l}\text { Which health behavior is common among patients with } \\
\text { low health literacy? }\end{array}$ & $\begin{array}{c}46 \\
(36.8 \% \\
)\end{array}$ & $\begin{array}{c}11 \\
(8.8 \%)\end{array}$ & $\begin{array}{c}47 \\
(37.6 \%)\end{array}$ & $\begin{array}{c}21 \\
(16.8 \%)\end{array}$ \\
\hline 6 & $\begin{array}{l}\text { Patients with low health literacy skills compared to } \\
\text { those with adequate health literacy: }\end{array}$ & $\begin{array}{c}36 \\
(28.8 \%)\end{array}$ & $\begin{array}{c}20 \\
(16.0 \%)\end{array}$ & $\begin{array}{c}22 \\
(17.6 \%)\end{array}$ & $\begin{array}{c}47 \\
(37.6 \%)\end{array}$ \\
\hline 7 & $\begin{array}{l}\text { What should the nurse consider when developing a } \\
\text { plan of care for a client with low health literacy }\end{array}$ & $\begin{array}{c}37 \\
(29.6 \%)\end{array}$ & $\begin{array}{c}14 \\
(11.2 \%)\end{array}$ & $\begin{array}{c}44 \\
(35.2 \%)\end{array}$ & $\begin{array}{c}30 \\
(24.0 \%)\end{array}$ \\
\hline 8 & $\begin{array}{l}\text { What is the priority action of the nurse when } \\
\text { conducting health teaching? }\end{array}$ & $\begin{array}{c}3 \\
(2.4 \%)\end{array}$ & $\begin{array}{c}7 \\
(5.6 \%)\end{array}$ & $0(0.0 \%)$ & $\begin{array}{c}115 \\
(92.0 \%)\end{array}$ \\
\hline 9 & $\begin{array}{l}\text { The recommended reading level for written healthcare } \\
\text { information is at or below: }\end{array}$ & $\begin{array}{c}40 \\
(32.0 \% \\
)\end{array}$ & $\begin{array}{c}38 \\
(30.4 \%)\end{array}$ & $\begin{array}{c}37 \\
(29.6 \%)\end{array}$ & $\begin{array}{c}10 \\
(8.0 \%)\end{array}$ \\
\hline $\begin{array}{l}1 \\
0\end{array}$ & $\begin{array}{l}\text { What is the best method to ensure that a health } \\
\text { brochure is culturally and linguistically }\end{array}$ & $\begin{array}{c}51 \\
(40.8 \% \\
)\end{array}$ & $\begin{array}{c}32 \\
(25.6 \%)\end{array}$ & $\begin{array}{c}22 \\
(17.6 \%)\end{array}$ & $\begin{array}{c}20 \\
(16.0 \%)\end{array}$ \\
\hline $\begin{array}{l}1 \\
1\end{array}$ & $\begin{array}{l}\text { What is the best method for the nurse to evaluate the } \\
\text { effectiveness of healthcare teaching? }\end{array}$ & $\begin{array}{c}92 \\
(73.6 \%)\end{array}$ & $\begin{array}{c}8 \\
(6.4 \%)\end{array}$ & $7(5.6 \%)$ & $\begin{array}{c}18 \\
(14.4 \%)\end{array}$ \\
\hline $\begin{array}{l}1 \\
2\end{array}$ & $\begin{array}{l}\text { When evaluating print materials for patients, what are } \\
\text { important aspects to consider? }\end{array}$ & $\begin{array}{c}13 \\
(10.4 \%)\end{array}$ & $\begin{array}{c}67 \\
(53.6 \% \\
\quad)\end{array}$ & $\begin{array}{c}16 \\
(12.8 \%)\end{array}$ & $\begin{array}{c}29 \\
(23.2 \%)\end{array}$ \\
\hline $\begin{array}{l}1 \\
3\end{array}$ & $\begin{array}{l}\text { Which title, for a health brochure on hypertension, } \\
\text { reflects best practice for written health instructions? }\end{array}$ & $\begin{array}{c}8 \\
(6.4 \%)\end{array}$ & $\begin{array}{c}14 \\
(11.2 \% \\
\quad)\end{array}$ & $\begin{array}{c}38 \\
(30.4 \%)\end{array}$ & $\begin{array}{c}65 \\
(52.0 \%)\end{array}$ \\
\hline $\begin{array}{l}1 \\
4\end{array}$ & $\begin{array}{l}\text { The nurse is caring for a patient newly diagnosed with } \\
\text { a health condition. What should be the priority focus } \\
\text { during the first teaching session? }\end{array}$ & $\begin{array}{c}19 \\
(15.2 \%)\end{array}$ & $\begin{array}{c}27 \\
(21.6 \%)\end{array}$ & $\begin{array}{c}39 \\
(31.2 \%)\end{array}$ & $\begin{array}{c}40 \\
(32.0)\end{array}$ \\
\hline
\end{tabular}

Clearly this suggests gap in health literacy knowledge among participants. Despite the need for nurses to understand health literacy and its impact on patients, the concept is not well known or understood by many nurses. 


\subsection{Nurses understanding of health literacy}

Most of the participants said that they had not heard this term before. Overall, they defined it understanding the term "health" and "literacy" and combining them. They related it as able to read and write with health. They stated that health literacy is knowing about healthrelated information like disease suffered, diagnostic test to do, which doctor to visit, able to read health related information and understanding health information given. Nurses mentioned that Low health literacy people has limited understanding. People with limited health literacy are unable to read the health information, they do not understand the given information even when said repeatedly and do not follow up the given health information at home compared to adequate health literate persons.

Participant nurses revealed that they have to deal with patient who does not understand given health information on large number and usually on daily basis. Nurses shared that it is very common problem in hospital setting to face situation when patient or patient's relative does not understand the given health information. They felt due to lower educational status large number of patients were unable to understand basic health information and services needed to make appropriate health decisions. They stated language barrier is common problem while they give health related instructions to patient. Nurses mentioned that some patients are found just smiling and nodding heads and pretending to understand the health information given. Nurse stated that patient unable to comprehend the given health information results in delay in medication, delay in decision making by patients and patient's relatives before carrying out important procedures, less likely to follow up instructions at home and patient returning back to ward due to ill health conditions as a result of failing to understand discharge instructions, They also stated that sometimes patients and patient's relatives misunderstand the given information resulting in medication error like wrong dosage and wrong time error.

For the effective communication and removing language barrier during health teaching, nurses stated that mostly they use of plain language and they try to speak in the language they understand (if they know). They also mentioned using of sign language and hand gestures, printed information, written information, pictures, pamphlets (if available) to give clear understanding about health information given. They mentioned that were taught to make patient understand the given health information by explaining in the language they understand along with coordinating with visitors in nursing schools. Nurses mentioned it is easy for them to work when the patient easily understands given information and will also save time. 


\section{DISCUSSION}

There is paucity of studies on the proficiency of health literacy among health professionals, especially nurses from south Asia. Furthermore, some reports have correlated low health literacy and health outcome of patients (Cavanaugh et al., 2010), subsequently identifying low health literacy in chronic ill patients is of equal important by health professionals. Therefore, our goal was to assess health literacy knowledge and practice amongst nurses working in BPKIHS, graduated from different universities of Nepal and few participants with foreign nursing educational background. Current study reported gap in health literacy knowledge among nurses.

Significant number of participants did not had knowledge that low health literacy patients are hospitalized more frequently for their chronic illness, participate less regularly in preventive healthcare, avoid asking questions and limited health literacy patients does not admit easily that they have difficulty in reading written materials, very few nurses knew teach-Back strategy to determine patient's understanding. It was evident in using health literacy screening for evaluating the written health care information for reading level, cultural appropriateness of materials.

Multiple previous studies have reported limited health literacy knowledge prevalent among nursing students (Cormier \& Kotrlik, 2009; Maduramente et al., 2019; Mibei \& Daniels, 2019; Williamson \& Chopak-Foss, 2015) and nurses working in different departments and settings of hospitals from different countries (Cafiero, 2013; Kennard, 2017; Nesari, 2017). However, Torres and Nichols reported that 391 associate-degree nursing students had knowledge about health literacy; however, they suggested that these students could benefit from additional educational opportunities that would reinforce that knowledge and skills in health literacy (Torres \& Nichols, 2014).

Results of our study finding showed that most of the participants were not aware of available health literacy screening tools, corresponding with previous studies (Cafiero, 2013; Chang et al., 2020; Kennard, 2017; Nesari, 2017), only 8\% participants were aware that the patients actual grade level of understanding is 3-5 grade lower than actual grade completed, while most of the participants thought patients with low health literacy could ask question, However, Katz et al had previously reported that low literacy patients ask fewer questions about their key medical issues and were less likely to seek out new information.

These behaviors reduce patients' ability to learn about their medical conditions and treatments. Medical personnel specially nurses should actively encourage patient participation in the clinical encounter, particularly when limited literacy skills are suspected (Katz et al., 2007). Nurses are educators who uses the concept of health literacy for 
assessment and identified the issues and uses easy to read instructions, health brochures, uses plain language to improve the communication with patients that will promote the disease management skills of patients (Bastable, 2017). However, evaluating and addressing the health literacy of individuals and selecting appropriate health education materials, ensure that a health brochure is culturally and linguistically appropriate were lacking among practicing nurses from Nepal. Indeed, with the aid of good health materials, health professionals could improve the extent to which they convey healthcare knowledge. We recommend that health literacy proficiency be strengthened in nurses' education to prepare them with adequate health literacy knowledge and skills.

Understanding the concept of health literacy and implementing evidence-based strategies to meet the health literacy demand of patient by nurses is of utter important (Johnson, 2015). Having a clear understanding of health literacy concept may lead to better health literacy practice. In bivariate analysis, health literacy knowledge score was not associated with any study variable which is concordant with study done among associate degree nursing students (Torres \& Nichols, 2014).

\section{STRENGTH AND LIMITATION}

To our best of knowledge, there is no such study among nurses from Nepal to find their knowledge of health literacy. Consequently, this study can be useful as it provides baseline data regarding nurses' understanding of health literacy. In addition, research in context of health literacy and nurses are limited in Nepal or worldwide. Thus, the finding of this study adds value to health literacy context and nursing literature. Despite the known numerous adverse effects of low health literacy on healthcare system, the finding of the study demonstrates that may be nurses from Nepal seems less prepared to tackle the growing problem of limited health literacy prevalent among patients. So, the concern policy makers can utilize it to put health literacy in place to produce effective manpower to deal with low health literacy and importance of transparency of health literacy in nursing education.

Firstly, the cross-sectional design does not allow conclusions about causality, and the present findings should be confirmed in follow-up studies. Second, the responses are Self-reported thus there could be chance of participant hiding their actual behavior and bias might have occurred. Lastly, the cronbach's alpha is less than generally accepted value. However, it could be due to a smaller number of questions. 


\section{CONCLUSION AND RECOMMENDATION}

If nurses have a clear understanding of health literacy concept this may lead to better understanding and to a better health literacy practice. Nurses are in best position to affect patient health literacy. Health care provider assume that they are proficient in identifying patient with limited health literacy, however study has shown that they fail to identify up to half of those patients (Rogers et al., 2006). Nurses being the prime responsible for educating the patients, it is of high important that their own proficiency level in health literacy must be high. Despite the need for nurses to understand health literacy and its impact on patients, the concept is not well known or understood by many nurses from Nepal. In our study out of total 14 questions, only four questions were correctly identified by more than half of participants and only three of these were correctly identified by more than $70 \%$ participants. Very less participants were aware about the teach-back strategies is an effective method to ensure effectiveness of healthcare teaching. This study uncovered the present gap in health literacy knowledge among nurses.

The current health workforce should understand the bulging problem of low health literacy prevalent among public. Gaps in knowledge can be filled through continuing education. Also, this study calls for integration of health literacy in nursing education to make future nurses competent in health literacy. 


\section{REFERENCES}

Baker, D. W. (2006). The meaning and the measure of health literacy. Journal of General Internal Medicine, 21(8), 878-883. https://doi.org/10.1111/j.15251497.2006.00540.x

Bastable, S. B. (2017). Nurse as Educator: Principles of Teaching and Learning for Nursing Practice (5th edition). Jones \& Bartlett Learning.

Budhathoki, S. S., Pokharel, P. K., Good, S., Limbu, S., Bhattachan, M., \& Osborne, R. H. (2017). The potential of health literacy to address the health-related UN sustainable development goal 3 (SDG3) in Nepal: A rapid review. BMC Health Services Research, 17(1), 237. https://doi.org/10.1186/s12913-017-2183-6

Cafiero, M. (2013). Nurse practitioners' knowledge, experience, and intention to use health literacy strategies in clinical practice. Journal of Health Communication, 18 Suppl 1, 70-81. https://doi.org/10.1080/10810730.2013.825665

Cavanaugh, K. L., Wingard, R., Hakim, R., \& iklizler, A. T. (2010). Low Health Literacy Associates with Increased Mortality in ESRD. J Am Soc Nephrol, 21(11), 1979-1985.

Chang, Y.-W., Li, T.-C., Chen, Y.-C., Lee, J.-H., Chang, M.-C., \& Huang, L.-C. (2020). Exploring Knowledge and Experience of Health Literacy for Chinese-Speaking Nurses in Taiwan: A Cross-Sectional Study. International Journal of Environmental Research and Public Health, 17(20), 7609. https://doi.org/10.3390/ijerph17207609

Cormier, C. M., \& Kotrlik, J. W. (2009). Health literacy knowledge and experiences of senior baccalaureate nursing students. The Journal of Nursing Education, 48(5), 237-248.

Institute of Medicine (US) Committee on Health Literacy. (2004). Health Literacy: A Prescription to End Confusion (L. Nielsen-Bohlman, A. M. Panzer, \& D. A. Kindig, Eds.). National Academies Press (US). http://www.ncbi.nlm.nih.gov/books/NBK216032/

Johnson, A. (2015). Health literacy: How nurses can make a difference. Australian Journal of Advanced Nursing, 33(2), 8.

Katz, M. G., Jacobson, T. A., Veledar, E., \& Kripalani, S. (2007). Patient Literacy and Question-asking Behavior During the Medical Encounter: A Mixed-methods Analysis. Journal of General Internal Medicine, 22(6), 782-786. https://doi.org/10.1007/s11606-007-0184-6 
Kennard, D. (2017). Emergency Room Nurses Knowledge of and Experience with Health Literacy and their Patient Teaching Methods. Seton Hall University Dissertations and Theses (ETDs). https://scholarship.shu.edu/dissertations/2270

Maduramente, T. S., Orendez, J. D., Saculo, J. A., Trinidad, A. L. A., \& Oducado, R. M. F. (2019). Health Literacy: Knowledge and Experience Among Senior Students in A Nursing College. INDONESIAN NURSING JOURNAL OF EDUCATION AND CLINIC (INJEC), 4(1), 9-19. https://doi.org/10.24990/injec.v4i1.227

Mibei, F., \& Daniels, F. (2019). Health Literacy Knowledge and Experiences of Nursing Students at a South African University. Africa Journal of Nursing and Midwifery, 21(1), 15 pages-15 pages. https://doi.org/10.25159/2520-5293/3205

Nesari, M. (2017, Spring). Health Literacy: Knowledge and Experiences of Iranian Registered Nurses. ERA. https://doi.org/10.7939/R3C53FD1C

Parker, R. (2000). Health literacy: A challenge for American patients and their health care providers. Health Promotion International, 15(4), 277-283. https://doi.org/10.1093/heapro/15.4.277

Perspectives of developing nursing education in Nepal. (2018). Nursing \& Care Open Access Journal, Volume 5(Issue 4). https://doi.org/10.15406/ncoaj.2018.05.00150

Rajah, R., Hassali, M. a. A., \& Murugiah, M. K. (2019). A systematic review of the prevalence of limited health literacy in Southeast Asian countries. Public Health, 167, 8-15. https://doi.org/10.1016/j.puhe.2018.09.028

Rogers, E. S., Wallace, L. S., \& Weiss, B. D. (2006). Misperceptions of medical understanding in low-literacy patients: Implications for cancer prevention. Cancer Control: Journal of the Moffitt Cancer Center, 13(3), 225-229. https://doi.org/10.1177/107327480601300311

Rudd, R. E. (2010). Improving Americans' Health Literacy INEJM. The New England Journal of Medicine, 363, 2283-2285. https://doi.org/DOI: 10.1056/NEJMp1008755

Shrestha, A., Singh, S. B., Khanal, V. K., Bhattarai, S., Maskey, R., \& Pokharel, P. K. (2018). Health Literacy and Knowledge of Chronic Diseases in Nepal. HLRP: Health Literacy Research and Practice, 2(4), e221-e230. https://doi.org/10.3928/2474830720181025-01

Sofaer, S., \& Schumann, M. J. (2013). This White Paper was prepared for the Nursing Alliance for Quality Care with grant support from the Agency for Healthcare Research and Quality (AHRQ) to the George Washington University School of Nursing. 32. 
Sørensen, K., Van den Broucke, S., Fullam, J., Doyle, G., Pelikan, J., Slonska, Z., Brand, H., \& (HLS-EU) Consortium Health Literacy Project European. (2012). Health literacy and public health: A systematic review and integration of definitions and models. BMC Public Health, 12(1), 80. https://doi.org/10.1186/1471-2458-12-80

Torres, R., \& Nichols, J. (2014). Health literacy knowledge and experiences of associate degree nursing students: A pedagogical study 1. Teaching and Learning in Nursing, 21(11), 84-92. https://doi.org/10.1016/j.teln.2013.11.003

Vaz de Almeida, C., \& Belim, C. (2020). Health Professionals' Communication Competences Decide Patients' Well-being: Proposal for a Communication Model. In A. T. Verčič, R. Tench, \& S. Einwiller (Eds.), Advances in Public Relations and Communication Management (pp. 201-222). Emerald Publishing Limited. https://doi.org/10.1108/S2398-391420200000005014

Walker, D., Howe, C., Dunkerley, M., Deupree, J., \& Cormier, C. (2019). The HLKES-2: Revision and Evaluation of the Health Literacy Knowledge and Experiences Survey. The Journal of Nursing Education, 58(2), 86-92. https://doi.org/10.3928/0148483420190122-05

WHO | Health is a fundamental human right. (n.d.). WHO; World Health Organization.

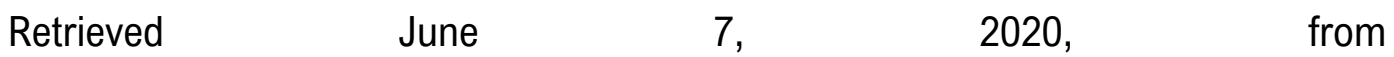
http://www.who.int/mediacentre/news/statements/fundamental-human-right/en/

Williamson, S. S., \& Chopak-Foss, J. (2015). Differences in health literacy knowledge and experiences among senior nursing students. 5(2), 7. 